\title{
ANTI-GANGLIOSIDE ANTIBODIES IN PATIENTS WTTH RHEUMATOID ARTHRITIS COMPLICATED BY PERIPHERAL NEUROPATHY
}

\author{
A. M. SALIH, N. B. NIXON, R. M. GAGAN, P. HEATH," C. P. HAWKINS, † P. T. DAWES and \\ D. L. MATTEY \\ Staffordshire Rheumatology Centre, The Hayu'ood, *Neurophysiology and †Neurology Depariments, Royal \\ Infirmary, Stoke-on-Trent
}

\begin{abstract}
SUMMARY
Gangliosides are a diverse class of glycolipids found in the plasma membrane of mammalian cells and are particularly abundant in cells of the nervous system. Serum antibodies to gangliosides have been detected in various neurological disorders with some evidence that they play a pathogenic role. In this study, we have investigated whether anti-ganglioside antibodies were elevated in a group of patients with rheumatoid arthritis (RA) who developed peripheral neuropathy (PN). An ELISA technique was used to test sera from 28 patients with RA and PN, 38 RA patients without PN and 20 normal controls for the presence of IgG and IgM anti-GMl and sulphatide antibodies. The patients with RA and PN had higher pain scores $(P<0.005)$, more extra-articular features $(P<0.05)$, higher erosive scores $(P<0.0001)$, lower haemoglobin $(P<0.005)$, higher ESR $(P<0.001)$ and were more often on disease-modifying drugs $(P<0.05)$. Twelve RA patients with PN $(43 \%)$, but only two RA controls $(5 \%)$, had positive titres against one or more gangliosides $(P<0.001)$. The neurologic disability score (NDS) correlated with RA duration $(P<0.05)$, and with levels of IgM anti-GM $1(P<0.001)$ and IgM anti-sulphatide $(P<0.05)$ antibodies. We conclude that PN is more common in patients with severe rheumatoid disease, and a significant proportion have elevated levels of anti-ganglioside antibodies.
\end{abstract}

KEY wORDS: Rheumatoid arthritis, Peripheral neuropathy, Anti-ganglioside antibodies, Neurologic disability score.

GANGliosides are a family of acidic glycolipids [1] which are composed of lipid (ceramide) and carbohydrate (oligosaccharide chain) moieties. Four gangliosides, GM1, GDla, GDlb and GTlb, are especially abundant in the brain, while LM1 constitutes the major ganglioside in peripheral nerves [2]. Sulphatide is the major acidic glycosphingolipid in myelin, and in peripheral nerves it is found in concentrations 100 times that of other gangliosides [3]. Gangliosides reside in the outer layer of the plasma membrane where they may regulate diverse physiological processes $[4,5]$, including neural cell function [6], cell-cell recognition, cell adhesion and the activity of enzymes such as protein kinase $\mathrm{C}$ and $\mathrm{Na}-\mathrm{K}$-ATPase. They influence neurite outgrowth [7] and possess neuroprotective functions. Previous studies have demonstrated beneficial effects from ganglioside administration in animal models of diabetes, leading to recovery in nerve conduction velocity and maintenance of axonal transport of cytoskeletal proteins [8]. In a study of patients with diabetic peripheral neuropathy (PN), ganglioside administration improved paraesthesiae and nerve conduction [9].

The abundance of gangliosides in the nervous system and their extracellular location make them potential antigenic targets in autoimmune neurological disorders. Antibodies to gangliosides have been found in a variety of neurological conditions, including

Submitted 26 September 1995; revised version accepted 10 February 1996.

Correspondence to: A. M. Salih, Staffordshire Rheumatology Centre, The Haywood, North Staffordshire Hospital, Stoke-onTrent ST6 7AG. multifocal motor neuropathy, distal and proximal lower motor neuron syndromes, and occasionally in Guillain-Barré syndrome and polymyositis [10]. The pathogenicity of anti-ganglioside antibodies has been suggested by the development of neuropathy and motor conduction block when these antibodies were injected in rabbits [11]. It has also been found that the IgM anti-GM1 antibodies react against the neuronal membranes by binding to the GM1 ganglioside [12].

Peripheral nerve involvement in rheumatoid arthritis (RA) can include compressive neuropathy, which is by far the commonest, and vasculopathy, resulting in distal sensory and combined sensorimotor neuropathy in $1-18 \%$ of patients [13]. Although the underlying pathology of rheumatoid neuropathy is not clear, humoral mechanisms such as the deposition of immune complexes and fixation of complement are thought to be important factors.

Histological examination of sural nerves has demonstrated deposition of $\mathrm{IgG}$, IgM, complement and fibrin in areas corresponding to those of fibrinoid necrosis [14]. As far as we are aware, no previous studies have examined the levels of anti-ganglioside antibodies in patients with $R A$ and peripheral neuropathy.

In this study, we have investigated the prevalence of anti-GM1 and sulphatide antibodies in patients with RA complicated by $P N$, and compared the results with measures of rheumatoid disease activity and damage.

\section{PATIENTS AND METHODS}

Consecutive patients with RA defined according to the ARA 1987 revised criteria [15], who were attending a district general hospital out-patient rheumatology 
TABLE I

Demographic details and indices of disease activity and damage in RA patients with and without peripheral neuropathy. Values given with confidence limits are means \pm S.D.

\begin{tabular}{lcc}
\hline & $\begin{array}{c}\text { PN } \\
(n=28)\end{array}$ & $\begin{array}{c}\text { RA controls } \\
(n=38)\end{array}$ \\
\hline Male:fernale & $10: 18$ & $8: 30$ \\
Age (yr) & $64 \pm 8$ & $60 \pm 9$ \\
Clinical indices & & \\
Duration of RA (yr) & $11.4 \pm 5.7$ & $9 \pm 6.2$ \\
Extra-articular & $n=6$ & $n=4$ \\
vasculitis & $n=7$ & $n=3$ \\
Early morning stiffness (min) & $45 \pm 32$ & $34 \pm 29$ \\
Visual analogue score (mm) & $65 \pm 17^{* * *}$ & $49 \pm 23$ \\
Disease-modifying therapy & $n=21^{* *}$ & $n=17$ \\
Lower limb operations & $n=13$ & $n=10$ \\
Laboratory indices & $11.9 \pm 1.4^{* * *}$ & $13.3 \pm 1.8$ \\
Haemoglobin (g/dl) & $53 \pm 28 * * * *$ & $28 \pm 25$ \\
ESR (mm/h) & $41 \pm 38$ & $35 \pm 64$ \\
CRP (mg/) & $228 \pm 276$ & $166 \pm 274$ \\
Rheumatoid factor & $345 \pm 809$ & $261 \pm 730$ \\
ANA & $166 \pm 50$ & $142 \pm 33$ \\
IgG (gm/l) & $171 \pm 75$ & $157 \pm 125$ \\
IgM (gm/l) & $80 \pm 28^{* * * * *}$ & $44 \pm 30$ \\
Larsen radiological score &
\end{tabular}

${ }^{*} P<0.05,{ }^{* *} P<0.01,{ }^{* * *} P<0.005,{ }^{* * * *} P<0.001,{ }^{* * * *} P<$ 0.0005 .

clinic between January and October 1994, were assessed for the presence of PN. The diagnosis was supported by nerve conduction studies. Patients had their neurological symptoms and signs assessed by the neuropathy symptom score (NSS) and the neurologic disability score (NDS), respectively [16]. The NSS is derived from a neurological history that is obtained in a standard way. Selected symptoms which occur in neuropathy are scored as present (1) or absent (0), with the total score being a summation of weakness, sensory and autonomic symptoms. The NDS is a measure of neurological deficit and includes cranial nerve evaluation, strength, deep tendon reflexes and sensory subsets. The strength is scored from (0) for normal power to (4) for complete weakness, while reflexes and sensation are scored $(0)$ for normal, (1) for decreased and (2) for absent responses. Thirty-eight consecutive RA patients without clinical symptoms or signs of PN, as judged by the NSS and the NDS, and 20 healthy volunteers (HV), were recruited as controls. None of the controls declined.

The following measures of RA disease activity and damage were recorded: duration of early morning stiffness, Ritchie articular index, $10 \mathrm{~cm}$ visual analogue scale for pain, presence of lower limb operations and extra-articular manifestations, and past or present medications with disease-modifying therapy.

Of the 28 patients with PN, 13 had extra-articular manifestations of RA, and of these seven patients had cutaneous, nail fold vasculitis or vasculitic ulcers on biopsy, while the remaining six had rheumatoid pulmonary complications, such as fibrosis, nodules and pleural effusion. One patient had Felty's syndrome.

Blood was taken for estimation of haemoglobin, ESR, CRP, IgM RF by ELISA, ANA, ANCA, cryoglobulins, immunoglobulins, complement, vitamin B12, folate, creatinine, thyroid-stimulating hormone, hepatic enzymes, blood glucose and anti-ganglioside antibodies. A standard chest radiograph was performed, and hands and feet films were graded by the Larsen score.

Patients with compression neuropathy or who had an alternative cause for PN, e.g. metabolic, infective, toxic or hereditary, were excluded. Four RA patients with diabetes and alcohol abuse were excluded.

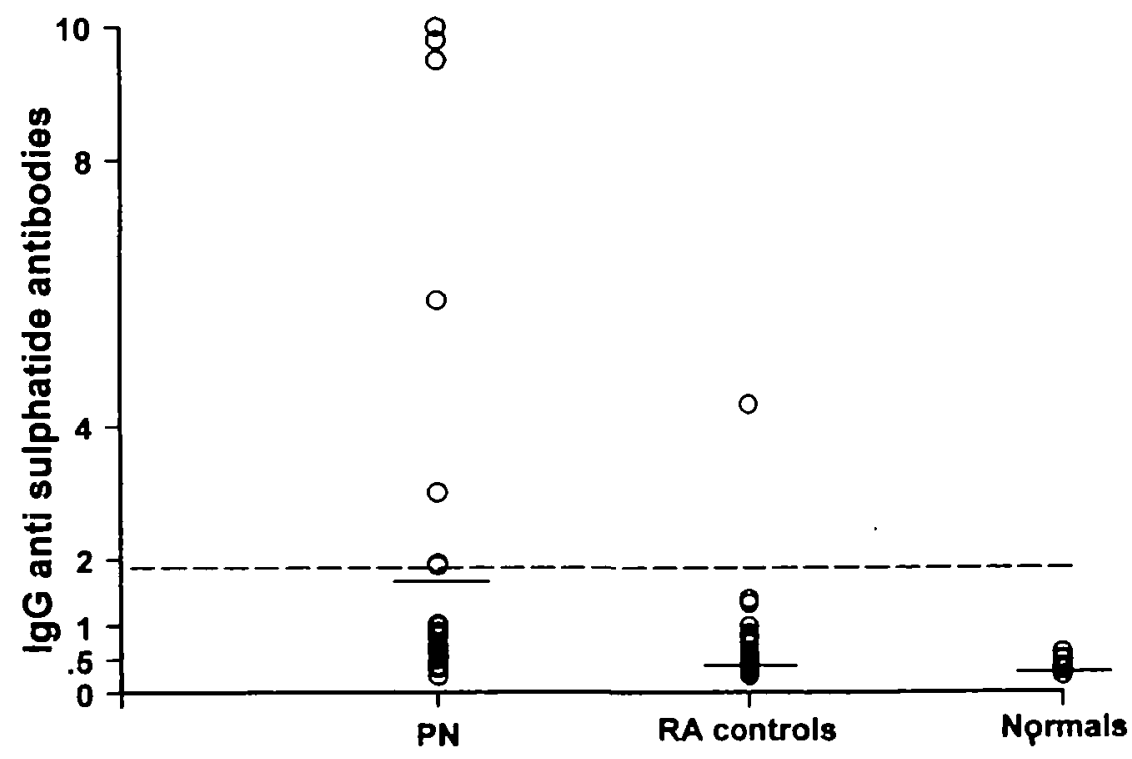

Patient Groups

Fio. 1.-Serum levels of IgG anti-sulphatide antibodies in patients with rheumatoid arthritis and peripheral neuropathy (PN), rheumatoid arthritis without peripheral neuropathy (RA) and normals (values shown are in arbitrary units). Values $>2$ s.D. of the mean for the RA controls were considered abnormal. _- mean for the RA controls + 2 s.D.; - mean for the PN, RA, normals. 


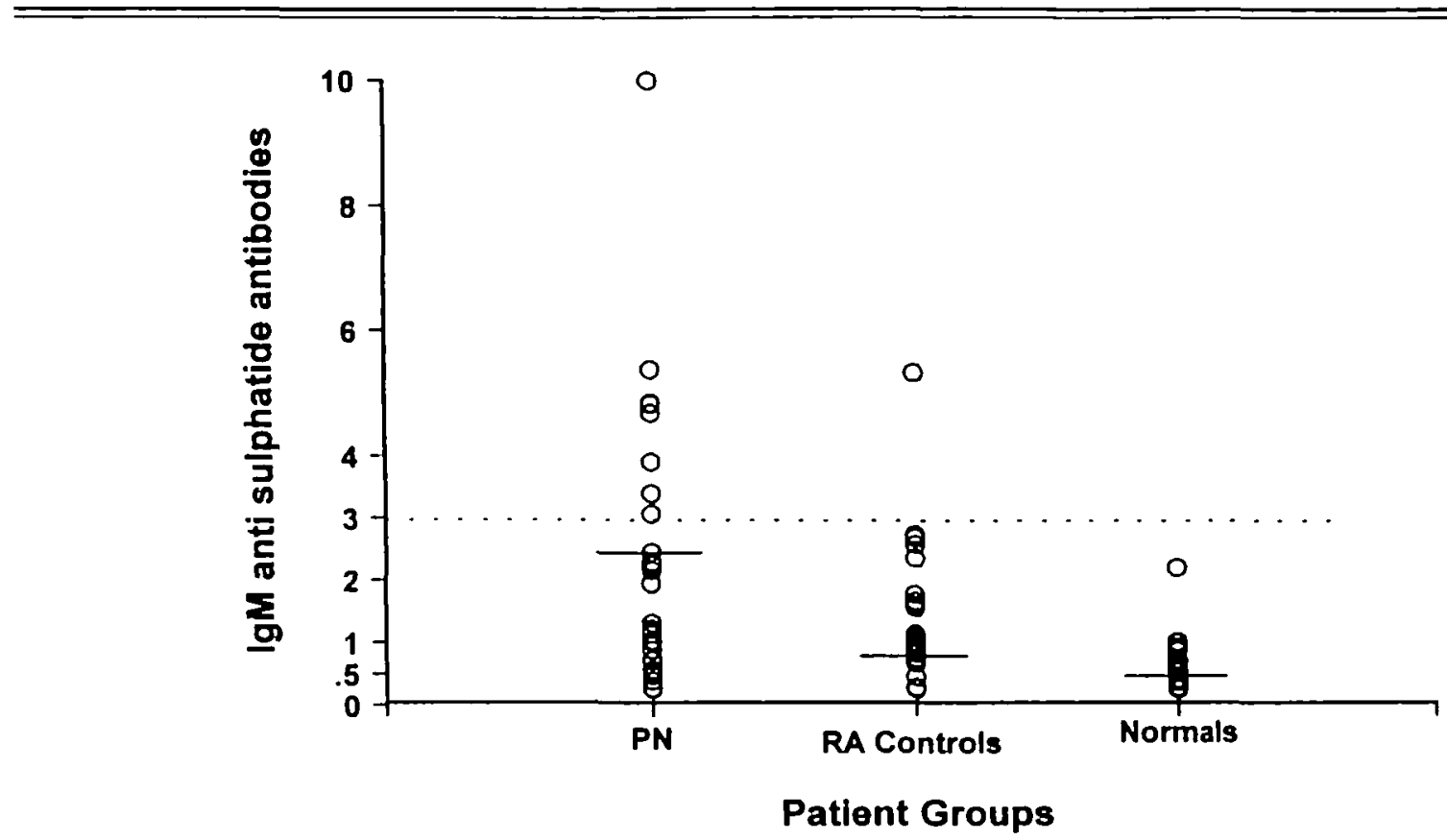

Fig. 2.-Serum levels of IgM anti-sulphatide antibodies in patients with rheumatoid arthritis and peripheral neuropathy (PN), rheumatoid arthntis without peripheral neuropathy (RA) and normals (values shown are in arbitrary units). Values $>2$ S.D. of the mean for the RA controls were considered abnormal. _- mean for the RA controls + 2 s.D.; - mean for the PN, RA, normals.

\section{Enzyme-linked immunosorbent assay (ELISA)}

A previously described technique was modified [17]. Commercially available (Sigma) bovine gangliosides GM1 and sulphatide were added to plastic microtitre plates at a concentration of $1 \mu \mathrm{g} / \mathrm{ml}$ in ethanol. After allowing ethanol to evaporate overnight at $4^{\circ} \mathrm{C}$, the plate was washed with phosphate-buffered saline (PBS) $/ 0.05 \%$ Tween and blocked by $0.1 \%$ human serum albumin in PBS/Tween for $1 \mathrm{~h}$. Each patient serum diluted 1:100 in PBS/Tween was added to duplicate wells and incubated for $2 \mathrm{~h}$ at room temperature. PBS/Tween alone was added to blank wells. A high and low control serum sample was incubated in each plate. After washing, alkaline phosphatase-conjugated anti-human IgG or IgM (1:1000 in PBS/Tween $+1 \%$ goat serum) was

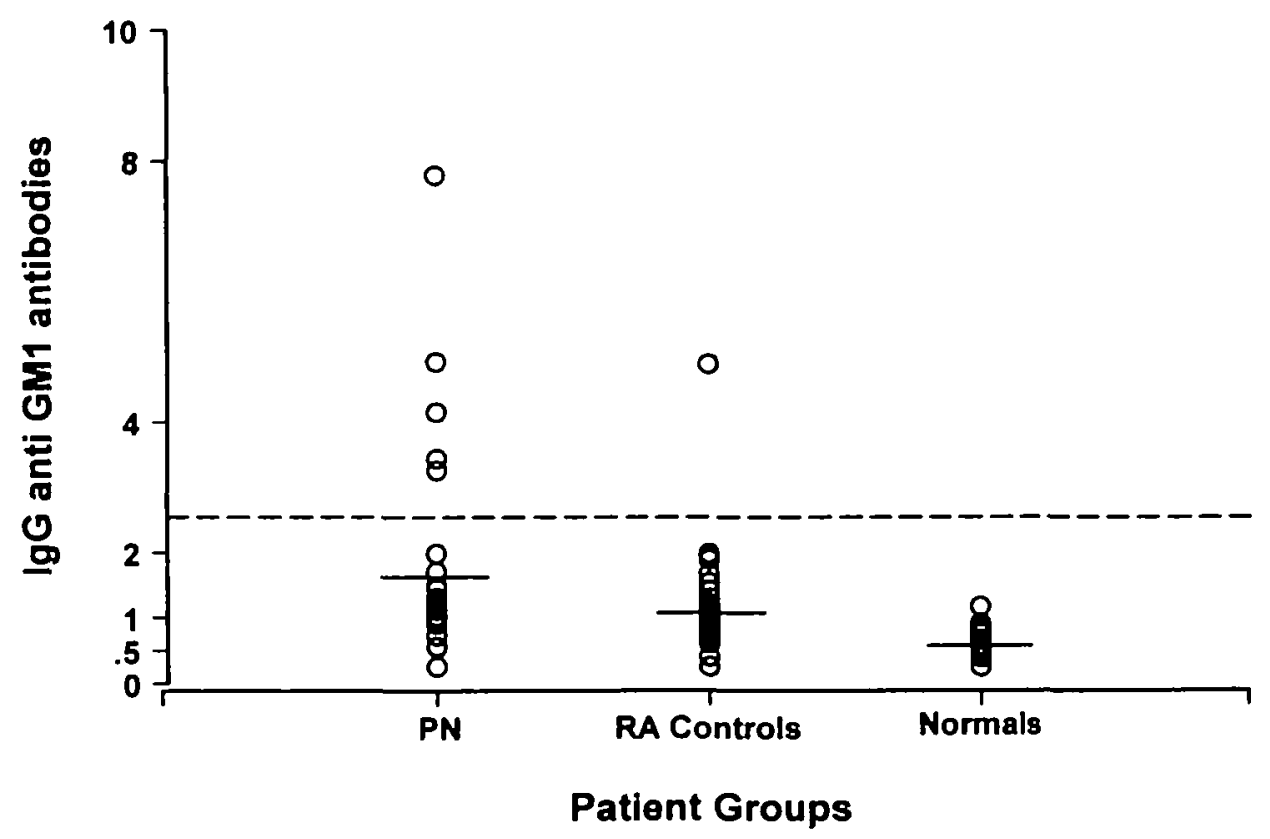

FIG. 3.-Serum levels of IgG anti-GMI antibodies in patients with rheumatoid arthritis and peripheral neuropathy (PN), rheumatoid arthritis without peripheral neuropathy (RA) and normals (values shown are in arbitrary units). Values $>2$ S.D. of the mean for the RA controls were considered abnormal. - mean for the RA controls + 2 s.D.; - mean for the PN, RA, normals. 


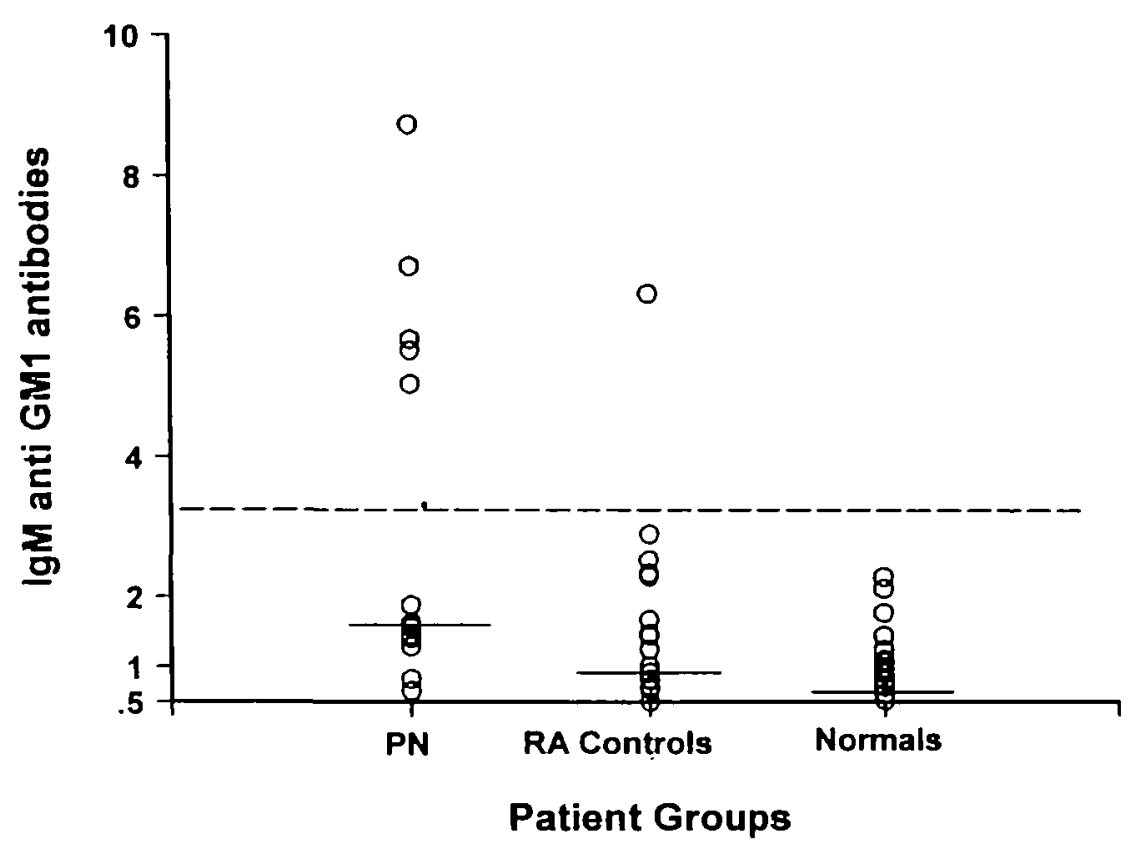

FIG. 4.-Serum levels of IgM anti-GMI antibodies in patients with rheumatoid arthritis and peripheral neuropathy (PN), rheumatoid arthritis without peripheral neuropathy (RA) and normals (values shown are in arbitrary units). Values $>2$ s.D. of the mean for the RA controls were considered abnormal. -...- mean for the RA controls + 2 s.D.; - mean for the PN, RA, normals.

added at $100 \mu \mathrm{l} /$ well for $1 \mathrm{~h}$ at room temperature. The plate was washed and incubated with $100 \mu \mathrm{l} /$ well of $1 \mathrm{mg} / \mathrm{ml} p$-nitrophenyl phosphate in diethanolamine buffer (Sigma) for $2 \mathrm{~h}$ (GM1) or $30 \mathrm{~min}$ (sulphatide) at room temperature.

A total of $50 \mu$ l of $3 \mathrm{M} \mathrm{NaOH}$ was added to each well to stop the reaction. The absorbance or optical density (OD) was read at $405 \mathrm{~nm}$ by an ELISA plate reader (Titertek Multiskan Plus MK11). A reference serum with high levels of antibodies was used to obtain a standard curve from which arbitrary units were determined. Values greater than two standard deviations of the mean for the RA control patients were considered to be abnormal. The intra- and interassay coefficients of variation were between 7.1 and $9.5 \%$ and 8.9 and $13.9 \%$, respectively, for the four assays.

\section{Absorption of sera with sulphatide}

To test for any cross-reactivity between antibodies to sulphatide and GMl, diluted sera $(1: 100)$ from $20 \mathrm{RA}$ patients with PN were incubated overnight with or without $100 \mu \mathrm{g} / \mathrm{ml}$ sulphatide in PBS/Tween.

An ELISA was then performed, as described above, to determine levels of IgM GMI antibodies with and without sulphatide absorption.

The percentage of antibody activity remaining after absorption was calculated as follows:

$$
\frac{\mathrm{OD} \text { (serum }+ \text { sulphatide) }-\mathrm{OD} \text { (blank) }}{\text { OD (serum only) }- \text { OD (blank) }} \times 100
$$

\section{Statistical analysis}

The significance of differences between the neuropathy and control groups was tested by the
Mann-Whitney $U$-test and correlations by Spearman's rank correlation.

\section{RESULTS}

Twenty-eight patients with PN were compared with the RA control group (Table I). The neuropathic group had a higher pain score $(P<0.005)$, more extraarticular features $(P<0.05)$, higher erosive scores $(P<0.0001)$, lower haemoglobin $(P<0.005)$, higher ESR $(P<0.001)$ and were more frequently on disease-modifying drugs $(P<0.05)$. However, age, RA disease duration, lower limb operations, early morning stiffness, CRP, rheumatoid factor, ANA and complement levels were not significantly different between the neuropathic group and their RA controls. RA patients with $P N$ had significantly higher IgG anti-sulphatide antibody levels than RA controls $(P<0.005)$ and HV $(P<0.0001)$. Levels of IgM anti-sulphatide antibodies were also raised among RA neuropathy patients compared to RA controls $(P<0.05)$ and HV $(P<0.001)$. IgG anti-GMI antibody levels were significantly higher in the neuropathic group than in the HV $(P<0.0001)$, but were not significantly greater than those in RA controls $(P=0.09)$. There were no statistical differences between the three groups of patients for IgM anti-GMI antibody levels, although the neuropathic group had a higher mean value.

Twelve patients (43\%) with RA and PN compared to two patients $(5 \%)$ from the RA control group had abnormal antibody levels against one or more gangliosides $(P<0.001)$, but none of the healthy volunteers had elevated levels, according to criteria used in this study (Figs 1-4). Seven patients with RA 


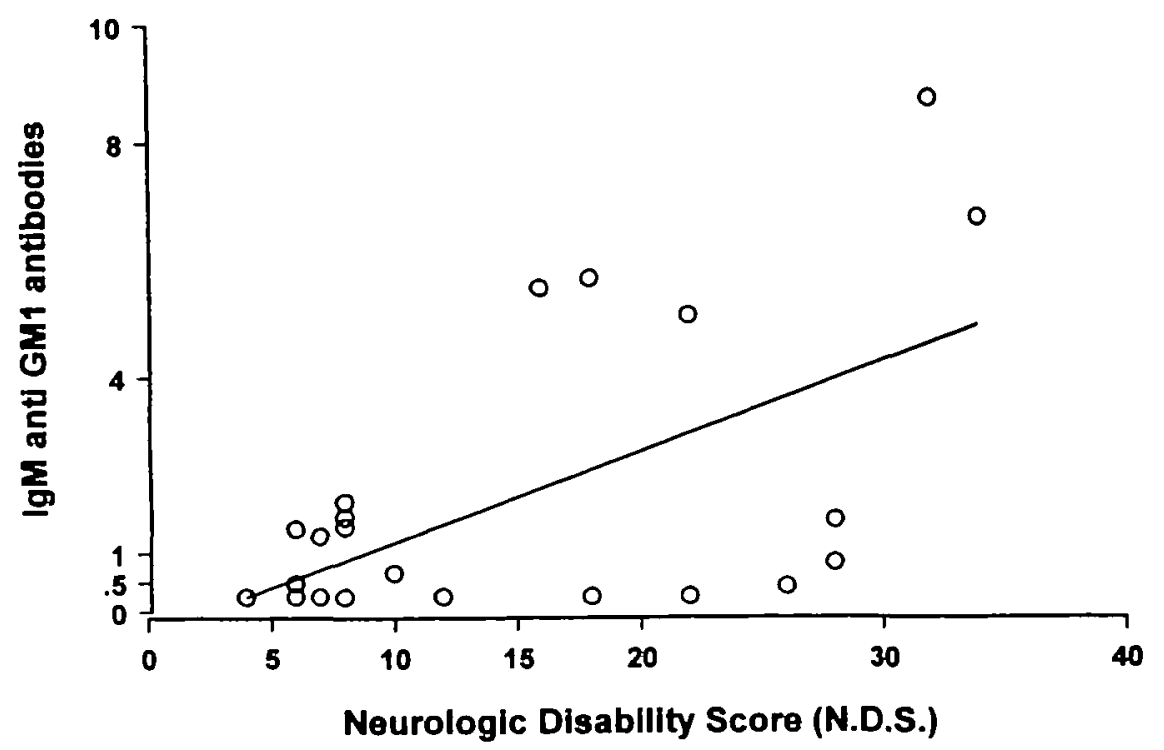

Fig. 5. - Correlation $(r=0.55, P<0.005)$ between IgM anti-GMI and the neurologic disability score.

and PN had abnormal antibody levels against more than one ganglioside.

There were significant correlations between IgM anti-GM1 and IgM anti-sulphatide antibodies $(P<0.0005)$, and between IgM anti-GMl and IgG anti-sulphatide antibodies $(P<0.0001)$. Four of 20 sera $(20 \%)$ from RA patients with PN absorbed with sulphatide demonstrated a $\geqslant 50 \%$ reduction in IgM anti-GM1 antibody levels. However, the majority of sera $(65 \%)$ showed little change $(<5 \%)$ in IgM GMl binding.

Those patients who demonstrated high antiganglioside antibody levels had lower $\mathrm{C} 4$ complement levels $(P<0.05)$. There was no significant correlation between the anti-ganglioside antibody levels and rheumatoid factor, and measures of RA disease activity or damage. Four patients with PN and elevated levels of anti-ganglioside antibodies had clinical evidence of vasculitis.

Neurophysiological studies revealed axonal polyneuropathy and mononeuritis multiplex in $10(36 \%)$ patients. Clinical sensorimotor neuropathy was found in 23 patients $(82 \%)$, while pure motor or sensory neurupathy was observed in two $(7 \%)$ and three $(11 \%)$ patients, respectively. The NDS correlated with RA duration $(P<0.05)$, and with the presence of IgM GM1 $(P<0.005)$ (Fig. 5) and IgM sulphatide $(P<0.05)$ antibodies.

\section{DISCUSSION}

We have demonstrated that a significant proportion of RA patients with PN $(43 \%)$ had abnormal anti-ganglioside antibody levels. In contrast, only $5 \%$ of RA patients without PN had elevated levels, while only low levels were found in sera of healthy volunteers. We found that PN occurs more frequently in patients with severe RA, which is in agreement with other studies [18].

We did not find a relationship between the anti-ganglioside antibodies tested and a clinical subset of neuropathy. This is explained by the majority of patients having a mixed sensorimotor presentation, and only a small number of patients having a pure motor or sensory neuropathy. Similarly, we are not able to relate the presence of the anti-gangliosides to axonal or demyelination changes because of the smaller number of patients with pure axonal features.

The presence of $\mathrm{PN}$ in patients with $\mathrm{RA}$ can be difficult to recognize as patients of ten relate neurological symptoms to joint disease. It is also difficult to assess the neurological system in the presence of severe joint disease. In this study, we used the NDS for the purpose of assessing severity and quantitating neurological deficit. Because the NDS is a global score of muscle weakness, reflex and sensory abnormality, it is thought to be one of the more robust measures of global neurological deficit, and its usefulness has been demonstrated in a trial of plasma exchange in patients with chronic inflammatory demyelinating polyneuropathy [19]. The sensitivity and reproducibility of NDS are established $[20,21]$

In our study, the presence of rheumatoid factor was not different in patients with and without PN, which suggests that it is not an important factor in the aetiology of neuropathy. There was evidence of complement $\mathrm{C} 4$ consumption in those neuropathy patients with high anti-ganglioside antibodies, suggesting that complement activation may play a pathogenic role.

Antibodies may be pathogenic or arise as a result of non-specific damage to neuronal tissues. It is not clear why patients with RA complicated by PN develop 
antibodies against gangliosides. It could relate to failure of tolerance by peripheral $T$ cells or be a result of molecular mimicry, as the ganglioside carbohydrate sequence is shared with bacterial lipopolysaccharide [22]. However, greater neurological deficit, as measured by the NDS, in those patients with higher anti-IgM antibodies against GMI and sulphatide molecules, indicates that these antibodies in RA PN are partly related to the severity of neuronal tissue breakdown.

Other clinical syndromes have been associated with defined anti-ganglioside specificity. IgM anti-GMI antibodies are found in $60-80 \%$ of patients with multifocal motor neuropathy [23] and IgM anti-sulphatide antibodies have been described in chronic axonal sensory neuropathy [24], while IgG anti-GQ1b antibodies are detected in patients with Miller Fisher syndrome [25]. In the present study, seven of the 12 patients $(58 \%)$ with anti-ganglioside antibodies had antibodies to both gangliosides, with significant correlations between the IgM and IgG antibodies to both gangliosides. The absorption experiments confirmed IgM cross-reactivity with both gangliosides in only $20 \%$ of the sera tested. This suggests that in the majority of patients clones of activated B cells are present which may produce antibodies to different gangliosides. These observations are in agreement with a previous study of patients suffering from lower motor neuron syndromes where there was only limited cross-reactivity with different gangliosides [26].

In conclusion, measurement of anti-ganglioside antibodies may prove to be helpful in the detection and assessment of PN in RA. Further work is needed to determine the pathogenicity of these antibodies and their relationship with the progression of neuronal pathology.

\section{ACKNOWLEDGEMENTS}

We would like to thank the Haywood Rheumatism Research and Development Foundation and North Staffordshire Medical Institute for supporting this study.

\section{REFERENCES}

1. Yu RK, Saito M. Structure and localization of gangliosides. In: Margolis RU, Margolis RK, eds. Neurobiology of glyco-conjugates. New York: Plenum Press, 1989:1-42.

2. Li Y-T, Mansson J-E, Vanier M-T, Svennerholm L. Structure of the major glucose-amine containing ganglioside of human tissues. J Biol Chem 1973;248:2634-6.

3. Svennerholm L, Fredman P. Antibody detection in Guillain-Barré syndrome. Ann Neurol 1980;27(suppl.): 36-40.

4. Merrill AH, Hannum YA, Bell RM. Introduction: sphingolipids and their metabolites in cell regulation. $A d v$ Lipid Res 1993;25:1-21.

5. Hakamori S. Bifunctional role of glycosphingolipids. $J$ Biol Chem 1990;265:18713-6.

6. Tettemanti G, Riboni L. Gangliosides and modulation of function of neural cells. Adu Lipid Res 1993; 25:235-67.

7. Consolazione A, Toffano G. Ganglioside role in functional recovery of damaged nervous system. In: Ledeen RW, Hogan EL, Tettamanti G, Yates AJ, Yu RK, eds. New trends in ganglioside research: Neurochemical and neuroregenerative aspects. Fidia Research Series. Liviana: Padova, 1988;14:523-33.

8. Figliomeni B, Bacei B, Panozzo C, Fogarolo F, Triban C, Fiori MG. Experimental diabetic neuropathy: Effect of ganglioside treatment on axonal transport of cytoskeletal proteins. Diabetes 1992;41:866-71

9. Pozza G, Galimberti G. Clinical uses of gangliosides in diabetic neuropathy. Diabetic Med 1993;10(suppl. 2): 95S-7S.

10. Sadiq SA, Thomas FP, Kilidirias $\mathrm{K}$ et al. The spectrum of neurological disease associated with anti-GMl antibodies. Neurology 1990;40:1067-72.

11. Thomas FP, Trojaborg W, Nagy C et al. Experimental autoimmune neuropathy in the rabbit with immunoglobulin deposits at nodes of Ranvier, following immunization with GM1 or Gal (beta 1-3) GalNAc. Ann Neurol 1990;28:238.

12. Thomas FP, Thomas JE, Sadiq SA et al. Human monoclonal IgM anti-Gal $(\beta 1-3)$ GalNAc autoantibodies bind to the surface of bovine spinal motoneurons. J. Neuropathol Exp Neurol 1990;49:89-95.

13. Conn DL, Dyck PJ. Angiopathic neuropathy in connective tissue diseases. In: Dyck PJ, Thomas PK, Lambert EH, Bunge R, eds. Peripheral neuropathy. Philadelphia: W B Saunders, 1984:2027-43.

14. Conn DL, McDuffie FC, Dyck PJ. Immunopathologic study of sural nerves in rheumatoid arthritis. Arthritis Rheum 1972;15:135-43.

15. Arnett FC, Edworthy SM, Bloch DA et al. The American Rheumatism Association 1987 revised criteria for the classification of rheumatoid arthritis. Arthritis Rheum 1988;31:315-23.

16. Dyck PJ, Sherman WR, Hallcher LM et al. Human diabetic endoneurial sorbitol, fructose, and myo-inositol related to sural nerve morphometry. Ann Neurol 1980; 8:590.

17. Pestronk A. Invited review: Motor neuropathies, motor neuron disorders, and antiglycolipid antibodies. Muscle Nerve 1991;14:927-36.

18. Conn DL, McDuffie FC. Neuropathy: The pathogenesis of rheumatoid neuropathy. In: Eberl R, Rosenthal M, eds. Organic manifestations and complications in rheumatoid arthritis. New York: F K Schattauer Verlag, 1976:295-306.

19. Dyck PJ, Karnes J, O'Brien P et al. Plasma exchange in chronic inflammatory demyelinating polyradiculoneuropathy. $N$ Engl J Med 1986;314:461.

20. Dyck PJ. Quantitating severity of neuropathy. In: Dyck PJ, Thomas PK, Grifin JW, Low PA, Poduslo JF, eds. Peripheral neuropathy. Philadelphia: W B Saunders, 1993:686-97.

21. Dyck PJ, Kratz KM, Lehman KA et al. The Rochester diabetic neuropathy study: design, criteria for types of neuropathy, selection bias, and reproducibility of neuropathic tests. Neurology 1991;41:799.

22. Yuki N, Taki $T$, Inagaki $F$ et al. A bacterium lipopolysaccharide that elicits Guillian-Barré syndrome has a GMI ganglioside-like structure. J Exp Med 1993; 178:1771-5.

23. Pestronk A, Chaudhry V, Feldman EL et al. Lower motor neuron syndromes defined by patterns of weakness, nerve conduction abnormalities, and high titres of antiglycolipid antibodies. Ann Neurol 1990; 27:316-26. 
24. Van den Berg LH, Lankamp CLAM, de Jager AEJ et al. Anti-sulphatide antibodies in peripheral neuropathy. $J$ Neurol Neurosurg Psychiatry 1994;56:1164-8.

25. Willison HJ, Veitch J, Paterson G, Kennedy PGE. Miller-Fisher syndrome is associated with serum antibodies to GQ1b ganglioside. $J$ Neurol Neurosurg Psychiatry 1993;56:204-6.

26. Chaudhry V, Pestronk A. Different patterns of glycolipid antibody reactivity: lower motor neuron syndromes vs. immunization. $J$ Neuroimmunol 1992;36:127-34. 